\title{
Hanseniase: crenças e tabus de agentes comunitários de saúde
}

Olga Maria de Alencar ${ }^{1}$, Thayza Miranda Pereira ${ }^{1}$, Jorg Heukelbach ${ }^{1}$, Jaqueline Caracas Barbosa ${ }^{1}$, Ana Suelen Pedroza Cavalcante ${ }^{1}$, Maria Rocineide Ferreira da Silva ${ }^{1}$

1. Universidade Estadual do Ceará, Fortaleza/CE, Brasil.

\section{Resumo}

Por meio da análise crítica do discurso, este artigo busca compreender na prática de agentes comunitários de saúde os discursos sobre a hanseníase/lepra, doença estigmatizada e envolta em saberes e práticas, tendo como premissa que esses profissionais incorporam representações preconcebidas ao trabalho. A pesquisa está estruturada de modo a familiarizar o leitor com os aspectos teóricos dessa análise e o percurso histórico dos profissionais na formação do discurso. Do corpus empírico emergiram as categorias: "comida reimosa: crenças e tabus alimentares"; "crenças e tabus relacionados ao álcool"; e "hanseníase, a doença que cai os pedaços". Foi revelado que os agentes acreditam na existência de alimentos reimosos e na culpabilização do álcool para o prolongamento do tratamento e que ainda circula a concepção de que a doença faz cair pedaços do corpo da pessoa acometida. Os conhecimentos técnicos equivocados dos agentes podem estar relacionados à forma como se dá a educação permanente.

Palavras-chave: Hanseníase. Discurso. Agentes comunitários de saúde.

\section{Resumen}

\section{Enfermedad de Hansen: creencias y tabúes de los agentes comunitarios de salud}

A través del análisis crítico del discurso, este artículo busca comprender los discursos sobre la enfermedad de Hansen/lepra, enfermedad estigmatizada e involucrada en conocimientos y prácticas, en la práctica de los agentes comunitarios de salud, con la premisa de que estos profesionales incorporen representaciones preconcebidas en su trabajo. La investigación se estructura con el objetivo de familiarizar al lector con los aspectos teóricos de este análisis y el recorrido histórico de los profesionales en la formación del discurso. Del corpus empírico surgieron las siguientes categorías: "alimentos remosos: creencias y tabúes alimentarios"; "creencias y tabúes relacionados con el alcohol" y "enfermedad de Hansen, la enfermedad que se desmorona". Se reveló que los agentes creen en la existencia de alimentos remosos y que el alcohol es el culpable de prolongar el tratamiento, y que sigue circulando la idea de que la enfermedad provoca la caída de pedazos del cuerpo de la persona afectada. El conocimiento técnico erróneo de los agentes puede estar relacionado con la forma en que se desarrolla la educación permanente.

Palabras clave: Lepra. Discurso. Agentes comunitarios de salud.

\begin{abstract}
Hansen's disease: beliefs and taboos of the community health agents

Using critical discourse analysis, this article seeks to understand the discourses on Hansen's disease/ leprosy, a stigmatized disease surrounded by knowledge and practices, in the practice of community health agents, based on the premise that these professionals incorporate preconceived representations into their work. The research is structured so as to familiarize the reader with the theoretical aspects of this analysis and the historical path of the professionals in the formation of the discourse. The empirical corpus led to the following categories: "reimoso [harmful] food: food beliefs and taboos"; "alcohol-related beliefs and taboos"; and "leprosy, the disease that makes the body fall apart." We found that the agents believe in the existence of reimoso [harmful] foods and in alcohol as the cause for prolonged treatment, and that the notion that the disease makes the body of affected people fall apart is still circulating. The agents' mistaken technical knowledge may be related to how continuing education occurs.
\end{abstract}

Keywords: Leprosy. Address. Community health workers. 
A hanseníase tem acompanhado o percurso humano ao longo da história, sendo incorporada a lendas e ao imaginário popular, e a explicação científica para sua causalidade surgiu apenas na era bacteriológica, com a descoberta do agente causador. Apesar disso, há uma tendência de pensá-la como doença do passado, principalmente no que se refere à dita "lepra bíblica". No Brasil esse pensamento é reforçado pela mudança do termo "lepra" para "hanseníase", em 1995, por meio da Lei 9.010/1995, que inaugurou um novo olhar sobre a doença ${ }^{1}$.

Neste estudo os dois termos são usados separadamente e de forma justaposta - hanseníase/ lepra -, dependendo do contexto. Quando se trata de aspectos histórico-culturais e da produção de sentidos e significados, adotam-se a terminologia "lepra" e seus derivados. Nos momentos em que são mencionadas políticas públicas e programas governamentais brasileiros, o vocábulo "hanseníase" e seus correlatos são usados. Já o termo hanseníase/lepra é empregado quando não se pode dissociar esses dois universos.

Trata-se de uma doença milenar cujos primeiros registros remontam a antigos papiros e a maioria dos estudiosos acredita ser originária do Egito, embora não haja consenso sobre isso ${ }^{2}$. A história da hanseníase/lepra está ligada a ideias de castigos e impurezas, citadas na Bíblia Sagrada como doença do pecado e de provação de fé ${ }^{3}$, sempre com a noção de purificação e não de cura. No evangelho de Mateus $(8,2-4)$ encontra-se a seguinte citação: $O$ homem com lepra dirigiu-se ao Senhor em súplica e foi milagrosamente purificado $^{4}$, recebendo ordens para cumprir suas obrigações determinadas por Moisés.

Apesar da descoberta do tratamento para a hanseníase, ainda persiste no imaginário popular a ideia de pecado ligada ao adoecimento, o que tem contribuído para o estigma que permeia a doença ${ }^{5}$, envolta em tabus e crenças de natureza simbólica desde épocas remotas e para muitos povos $^{6}$. O termo "estigma" é usado para designar um atributo depreciativo ou se referir a estereótipos criados para diferenciar indivíduos fora do padrão de normalidade imposto pela sociedade ${ }^{7}$. Assim, parte-se da premissa de que práticas discursivas e conhecimentos dos sujeitos sobre a hanseníase/lepra resultam de um processo historicamente construído.

No cotidiano dos serviços de saúde, a hanseníase é curável e de fácil controle, mas, pelo prisma cultural, ela remete a símbolos, representações e imagens construídas coletivamente em diversos contextos. Portanto, trata-se de doença polissêmica e multifacetada que é elemento-chave para compreensão da inevitável associação entre as dimensões física, psicológica e sociocultural. Assim, compreender saberes e ações que permeiam os serviços de saúde é relevante, uma vez que as práticas discursivas dos agentes comunitários de saúde (ACS) são socialmente construídas, sendo inevitavelmente incorporadas ao seu processo de trabalho.

Os ACS foram institucionalizados por meio do Programa Agente Comunitário de Saúde (Pacs), criado em 1991 pelo Ministério da Saúde (MS) e consolidado como estratégia para reorganizar o modelo de atenção à saúde ${ }^{8-10} \mathrm{com}$ a implantação do Programa Saúde da Família (PSF), em 1994. Dentre as atribuições dos ACS, trabalhadores exclusivos do Sistema Único de Saúde (SUS), estão prevenção de doenças e promoção da saúde mediante ações domiciliares ou comunitárias, individuais ou coletivas, desenvolvidas em conformidade com as diretrizes do SUS ${ }^{9}$. Estas definem que os ACS devem realizar vigilância de doenças e acompanhamento sistemático da população sob sua responsabilidade ${ }^{11}$.

No campo da saúde, o discurso dos ACS reflete seu modo de pensar, ser e agir em relação a diferentes aspectos do processo de adoecimento da hanseníase/lepra, o que indica influência mútua com o meio. Assim, contexto social e discursos parecem ser "flexíveis" às mudanças do cotidiano e ao conhecimento que os sujeitos - ACS - produzem de si mesmos em sua relação com o mundo material ${ }^{12}$. Nesse sentido, a análise crítica do discurso (ACD) desvela-se como possibilidade teórico-metodológica de explicação dos fenômenos discursivos dos ACS.

A ACD leva em conta a complexidade e as articulações do discurso, já que este é formador de ações, assim como as práticas podem constituir diferentes discursos ${ }^{13}$. Neste estudo a ACD é usada como teoria-método para compreender a produção discursiva de ACS acerca da hanseníase e consequentemente sua prática social. O discurso é definido como prática social e não atividade de cunho individual, sendo considerado como um modo de ação pelo qual pessoas e coletivos agem sobre o mundo e sobre os outros, bem como um modo de representação e significação ${ }^{13}$. 
Os discursos são parte do recurso utilizado por atores sociais para se relacionarem, cooperando, competindo e dominando ${ }^{14}$. Portanto neles estão presentes ideologias e relações de poder. Assim, a partir do exposto, busca-se compreender o significado da lepra/hanseníase para ACS nos contextos pessoal e profissional, identificando crenças, valores e tabus que possam contribuir para o estigma da hanseníase em seu trabalho.

\section{Materiais e métodos}

Trata-se de estudo exploratório e descritivo com abordagem qualitativa realizado nos munícipios de São José de Ribamar/MA e Floriano/PI, ambos situados no Nordeste brasileiro. Para participar da pesquisa, foram selecionados ACS que atuam na Estratégia Saúde da Família (ESF) com base nos critérios a seguir: atuação como ACS há mais de dois anos; participação de no mínimo um ACS por unidade básica de saúde; e local de trabalho em zona urbana. Foram utilizadas duas questões disparadoras: 1) o que significa hanseníase/lepra para você?; e 2) o que significa trabalhar com hanseníase/lepra?

Para coleta de dados, empregou-se o grupo focal, técnica qualitativa utilizada para entender como se formam as diferentes percepções e atitudes acerca de um fato, prática, produto ou serviço ${ }^{15,16}$. Os participantes foram selecionados mediante convite enviado por meio da coordenadora da atenção primária municipal para que todos os ACS da zona urbana que atuam na ESF participassem da reunião com as pesquisadoras. Após explicação da proposta de pesquisa e seus desdobramentos, os ACS que aceitaram participar foram divididos em dois grupos, com data e local pactuados coletivamente.

Participaram do estudo 46 ACS - 20 de Floriano/ PI e 26 de São José de Ribamar/MA -, com média de idade de 23 anos, sendo a mínima 22 e a máxima 69 anos, dos quais $92,3 \%$ eram mulheres e $50,1 \%$ estavam na faixa etária de 30 a 39 anos. Sobre o nível de escolaridade, $86,8 \%$ relataram ter o ensino médio completo, $7,4 \%$ têm ou estão cursando o ensino superior e $5,8 \%$ não responderam ou referiram outra escolaridade.

Para coleta das informações, um roteiro semiestruturado foi elaborado por pesquisadoras com experiência em abordagem qualitativa. As discussões foram gravadas em áudio e transcritas por pessoa especializada no assunto, com validação posterior da autora principal. As falas foram analisadas por meio da ACD com objetivo de possibilitar a reflexão sobre as condições de produção e apreensão da significação, além da compreensão do modo de funcionamento, dos princípios de organização e das formas de produção dos sentidos ${ }^{13,14,17}$.

Para apropriação do conteúdo das falas por meio da ACD seguiram-se os passos propostos por Minayo ${ }^{17}:$ 1) transcrição do material colhido no grupo focal; 2) leitura flutuante do material, intercalando com escuta exaustiva da gravação em busca do afloramento dos temas para que os investimentos afetivos emerjam; e 3) construção ou mapeamento dos temas (categorias empíricas).

Este estudo faz parte do projeto "Padrões epidemiológicos, clínicos, psicossociais e operacionais da hanseníase nos estados do Maranhão, Pará, Tocantins e Piauí: uma abordagem integrada" ${ }^{18}$, vinculado ao edital de pesquisa de doenças negligenciadas publicado pelo Departamento de Ciência e Tecnologia (Decit) e pelo Conselho Nacional de Desenvolvimento Científico e Tecnológico (CNPq) (Edital 34/2008) a partir da demanda do Programa Nacional de Controle da Hanseníase (PNCH) envolvendo esses estados ${ }^{19}$.

O projeto de pesquisa foi aprovado pelo comitê de ética da Universidade Federal do Ceará (UFC), conforme preconiza a Resolução CNS $466 / 2012$, que normatiza pesquisa envolvendo seres humanos ${ }^{20}$. Os participantes colaboradores, após explicação, assinaram o termo de consentimento livre e esclarecido.

\section{Resultados e discussões}

Como outras doenças graves, a hanseníase é estigmatizada e está associada a crenças populares, especialmente sobre o que a causa, quem a contrai e como deve ser reconhecida e tratada ${ }^{21}$. Emergiram dos discursos das ACS as categorias: 1) comida reimosa: crenças e tabus alimentares; 2) crenças e tabus relacionados ao uso de álcool; e 3) hanseníase, a "doença que cai os pedaços".

\section{Comida reimosa: crenças e tabus alimentares}

No senso comum, uma das causas atribuídas à hanseníase é a ingestão de certos alimentos, 
com base em observações realizadas nos lugares onde a doença existia de forma endêmica. A prática proibitiva e a vigilância institucionalizada referida por Foucault ${ }^{22}$ são presença constante nas orientações dos ACS, na maioria das vezes reforçadas e justificadas pelo discurso de outros profissionais de saúde. Assim, incrimina-se a ingestão de alguns alimentos, como carne suína, referenciada no discurso a seguir.

"(...) Eu disse pra ela que é uma doença como outra qualquer, que se ela fizesse o tratamento direitinho, a partir da segunda semana, né, ela já não transmitia mais (...) o médico também falou pra ela a mesma coisa (...) sobre a comida, eu disse pra ela não comer carne de porco - porque dizem que é reimoso, né? - e pato (...)" (Grupo focal 7).

No discurso dos ACS, determinados alimentos são referidos como na linguagem popular e reforçados como maléficos, sendo obrigatória, portanto, sua exclusão da dieta. Essa prática é validada pela fala do médico e da enfermeira, corroborando a prática discursiva do ACS.

"Em relação ao marisco aí, eu fui orientada pela enfermeira e pelo médico (...) que acompanham o meu esposo: ele não poderia comer marisco. Aí eu até disse pra ela que ele gostava muito de camarão, né, que toda vez que a gente [ia] pra freira ele queria trazer camarão. Aí ela disse que não, que era pra evitar o camarão. Eu digo que não pode. Eu digo que não pode já pra prevenção, entendeu? Eu digo que não pode" (Grupo focal 8).

"Carne de porco. Eu peço pra ele [paciente] evitar. [Para] todos os que eu acompanho eu peço pra eles evitar (...) como diz assim, deixar a poeira baixar pra poder comer (...)" (Grupo focal 8).

Perpetuar essas proibições é cruel e descontextualizado, uma vez que os participantes deste estudo, em sua maioria, moram em comunidades litorâneas, onde peixe e marisco são alimentos de fácil acesso. Nesse sentido, os hábitos alimentares de pessoas acometidas por hanseníase sofrem influência direta de seu contexto social e econômico $^{23}$. Cabe aqui uma reflexão: não estariam os profissionais de saúde perpetuando práticas descontextualizadas? Ou: por que os profissionais de saúde, a quem a população tem como referência, são tão normativos em suas orientações?
No livro Vigiar e punir, Foucault ${ }^{22}$ postula a forma como os serviços de saúde normatizam a vida das pessoas. Isso é exemplificado nos próximos trechos, que trazem regras ditadas pelos ACS e materializadas em representações formadas na interface do contexto do trabalho com as normas estabelecidas no meio social em que vivem.

"Em relação ao marisco (...) fui orientada pela enfermeira e pelo médico (...) que não poderia comer marisco (...) eu digo que não pode pra prevenir (...)" (Grupo focal 7).

"Carne de porco. Eu peço pra ele evitar. (...) eu peço pra eles evitar (...) Deixar melhorar, (...) deixar a poeira baixar pra poder comer (...) é melhor evitar um pouquinho até a medicação fazer mais efeito (...)" (Grupo focal 8).

"(...) Nas comunidades que a gente visita, eu acho que já é assim, já sabem que a carne de porco (...) certo tipo de peixe (...) já não comem, já chega à banca e diz: 'Eu quero aquele peixe que 'mulher parida' come'. Já diz assim, que não faz mal a ninguém, não é reimoso (...)" (Grupo focal 3).

Os ACS utilizam os termos populares "reimoso" e "reima" para representar os alimentos "maléficos", que devem ser excluídos da dieta de pacientes com hanseníase, principalmente durante o tratamento. "Reima" deriva de rheuma, que designa "mau gênio" ou uma "qualidade" do alimento que o torna ofensivo para certos estados do organismo e em certos momentos da vida ${ }^{24}$. Dentre os alimentos mais citados como reimosos e que, portanto, devem ser terminantemente proibidos, estão caça (animais selvagens), carne de porco, peixes de pele e frutos do mar.

"(...) a minha familia, quando teve [hanseníase] também, eles não comiam nem camarão, nem caranguejo, nem carne de porco" (Grupo focal 8).

"(...) eu sempre oriento o seguinte: (...) te alimenta bem porque a medicação é pesada, tenha uma boa alimentação, você pode comer bastante fruta, (...) verdura. Eu sempre peço, por meu risco próprio, que a pessoa que faça uso desse tipo de medicação não coma limão, porque limão é ácido (...). Então eu sempre peço, se vocês puderem evitar o limão evitem (...) limão é muito ácido (...) não pode deixar de se alimentar corretamente, porque essa medicação é uma medicação forte (...)" (Grupo focal 7). 
Preferências e restrições alimentares são geralmente de origem social ou cultural e, quando compartilhadas pelo mesmo grupo social, podem constituir tabus alimentares, influenciando atitudes e comportamentos, bem como a forma de representar o mundo dos sistemas sociais ${ }^{25}$. Assim, essas restrições podem relacionar-se a tabus ligados ao senso comum, ocasionando a proibição do consumo de determinados alimentos por possuírem reima e representarem perigo para a saúde ${ }^{26,27}$.

\section{Crenças e tabus relacionados ao uso de álcool}

O alcoolismo representa grave problema mundial, pois é insidioso e interfere nos cuidados pessoais e comportamentos, trazendo consequências para a saúde e provocando mudanças nos hábitos dos indivíduos ${ }^{28,29}$. As representações sobre o uso do álcool associado à hanseníase que os ACS fazem dos indivíduos etilistas são provenientes do imaginário coletivo e carregadas de juízos de valor negativo. Além disso, a bebida alcoólica é referida como inapropriada por interferir no tratamento.

“(...) Não beber, não tomar bebida alcoólica (...). Se tomar bebida alcoólica, ali já não serve a medicação, aí ela vai ter que começar novamente, já é reincidente, aí tem que começar outro tratamento (...)" (Grupo focal 4).

O uso da bebida alcoólica é considerado um fator que impossibilita tanto a adesão à terapia como sua regularidade ${ }^{30}$. Por isso, essa relação é marcada nos discursos dos ACS como determinante para prolongar a duração do tratamento, caso o paciente não siga as orientações.

"(...) no caso da bebida (...) tem paciente que bebe (...). Tem que parar de beber pra tomar aquele remédio. Se o médico passou que você vai tomar esse remédio [por] seis meses, se ele beber vai aumentar pra um ano, dois anos (...)" (Grupo focal 4).

O discurso que proíbe o consumo de álcool durante o tratamento da hanseníase apresenta conteúdos centrados no saber biomédico incorporados à prática cotidiana dos ACS, pois o etilismo é um dos fatores associados ao abandono ${ }^{30}$. Além disso, o abandono e a irregularidade da terapia sempre causaram preocupações para os trabalhadores de saúde, uma vez que podem implicar a manutenção da cadeia de transmissão e a instalação de sequelas e complicações, bem como o desenvolvimento de resistência à poliquimioterapia ${ }^{31,32}$.

$\mathrm{O}$ abandono a partir do fator de risco alcoolismo pode ter como determinante a forma como os profissionais tratam a questão, mas também decorrer de fatores relacionados ao esquecimento dos pacientes. Assim, o ACS tem papel fundamental no monitoramento do tratamento desses pacientes.

\section{"Doença que cai os pedaços"}

A expressão "doença que cai os pedaços" é usada pelos ACS quando se referem às sequelas, sendo comuns no discurso deles relatos sobre "perdas de dedos" associadas à hanseníase, o que indica que esses profissionais não compreendem que isso ocorre em razão da falta de cuidados preventivos e não como sequela inevitável.

"(...) Aí eu disse 'meu Deus! (...) essa doença não é aquela que cai os pedaços da pessoa?' (...)" (Grupo focal 8).

O serviço de saúde exige que os ACS orientem a comunidade sobre a doença e monitorem os casos, no entanto, não fica claro se ele os prepara para desenvolver essas ações e, quando prepara, se a preocupação se limita à vigilância da doença, com foco no diagnóstico e tratamento, ou abrange questões socioculturais do adoecimento. É pressuposto que cuidar de pessoas com hanseníase não se limita a diagnóstico e cura, pois há questões ideológicas no processo histórico da doença. Assim, o ACS atua como mediador entre o saber popular e o científico normatizado pelos serviços de saúde ${ }^{33-35}$, função evidenciada em falas somo as seguintes:

"(...) é uma doença infecciosa, (...) antigamente havia outro nome (...) lepra. (...) Quando eu era jovem no interior, eu presenciei uma pessoa que morreu por falta de cuidados. (...) por causa dessa doença, ela ficava naquele cantinho reservado, ninguém tocava. (...) eu presenciei o sofrimento dela vários tempos. Ela teve várias feridas, criou até bicho (...) por falta de cuidado, (...) aquela coisa feia, eu disse 'meu Deus (...) só aqueles ossinhos nos dedinhos (...)"' (Grupo focal 8).

O denso investimento metafórico historicamente dirigido à lepra é um processo repleto de significados morais em que o sentido associado à 
perda de membros se materializa na fusão entre o conhecimento científico e o popular ${ }^{36}$. O discurso popular no diálogo do ACS é constantemente pronunciado e, muitas vezes, mesclado com o saber embasado na ciência, principalmente quando se trata da justificação da perda de membros em virtude do diagnóstico tardio ou do não seguimento do tratamento como prescrito.

"(...) ah, a lepra, ah, se não tratar, aí cai um pedaço (...)" (Grupo focal 4).

"(...) Eu também acompanhei um rapaz, ele, eu acho que ele fez foi cair o pedaço do dedo, não sei se caiu mesmo. Mas ele disse que fez foi cair. Ele começou o tratamento cedo, só que ele bebia, aí ele disse que começou a ferir, a ferir $e$ ficou só no osso (...)" (Grupo focal 7).

A imagem da lepra evoca imediatamente seus sintomas físicos mais graves, como as deformidades, muitas vezes confundidas com perda de membros do corpo. Desse modo, a utilização do termo "hanseníase" parece atenuar a patologia e diferenciá-la da lepra em suas consequências. Isso pode ser evidenciado em sua representação como uma enfermidade complexa, que apresenta várias formas e estágios, inclusive em seu nome.

"(...) antigamente, (...) a gente via aquele povo todo ferido: 'Fulano tá com lepra', (...) 'Minha mãe sempre dizia: Olha... assim, assim, ele ta com lepra...' porque lá [no interior] era assim. Hoje já não tem mais aquelas feridas no corpo assim. (...) A lepra era mais grave, quando ela se apresentava, ela era mais grave. (...) a lepra já é uma doença mais avançada, (...) bem mais avançada (...) que a hanseníase, (...) quando descobria, já tava num estado avançado" (Grupo focal 3).

"(...) existe a fase da doença que acontece [as sequelas]. (...) depois de um tempo que ela não é tratada, ela vai avançando. Quando chega a atrofiar, já vem de muito tempo. (...) está nos últimos estágios" (Grupo focal 4).

O conhecimento dos ACS sobre hanseníase pode estar relacionado ao tempo de serviço, nível de estudo e capacitações realizadas ${ }^{37}$, o que evidencia a importância da educação permanente sobre a doença para esses profissionais. Além disso, deve-se levar em consideração o papel fundamental dos
ACS na busca ativa e detecção precoce dos casos, uma vez que têm contato mais próximo com a população em seus territórios ${ }^{38}$. Assim, quando utilizam, equivocadamente, palavras como "multibacilar", "doença crônica" e "sequela" para designar formas de apresentação da doença, estão confrontando o que consideram representação do senso comum.

"Doença de mais e menos mancha (...) com os conhecimentos técnicos adquiridos durante sua formação (...) uma doença crônica, infecciosa. Uma doença que atinge a pele (...) nervos (...) mão, orelhas, dedos, pés (...) tem de várias formas, tem multibacilar, que é o que tem mais e menos [manchas], sente mais dor $e$ sente menos dor (...)" (Grupo focal 3).

"(...) são três tipos? Até onde eu tenho conhecimento, o meu treinamento, são três tipos (...). Tem um [em] que o grau é mais elevado, no caso dos nervos (...) Multibacilar? Aliás, menos é nos nervos e o grau mais elevado é na pele, porque quando ele chega a atingir a pele você fica deformado" (Grupo focal 7).

Outros estudos apresentaram resultados semelhantes ao referirem que, do ponto de vista das ciências biomédicas, a hanseníase conta com tratamento e cura, mas, pelo prisma cultural, ela remete a símbolos negativamente carregados num número considerável de sociedades ${ }^{39,40}$. Da mesma forma, as metáforas utilizadas pelos ACS são representações para a compreensão da inevitável associação entre as dimensões física, psicológica e sociocultural da hanseníase/lepra.

\section{Considerações finais}

Há vários equívocos conceituais na prática dos ACS, como a associação da forma multibacilar à dor e o entendimento de que a doença apresenta várias formas - multibacilar, com mais e menos manchas, com mais dor e menos dor, bem como a forma antiga: "a doença que cai os pedaços". Considerando que essas construções sociais e simbólicas ajudam a manter o estigma da doença, entende-se a importância dos conhecimentos produzidos nesses discursos. Isso aponta para as metodologias propostas na formação dos ACS, como também para inexistência de práticas de educação permanente pautadas na aprendizagem significativa, às quais tais equívocos podem estar relacionados. 
Este estudo buscou refletir sobre a necessidade de estabelecer ações de educação permanente que mobilizem esses profissionais a identificar estratégias que utilizem múltiplas linguagens, aproximando-se das realidades vivenciadas nos territórios, a fim de modificar o atual cenário da hanseníase e superar modelos centrados na doença.

\section{Referências}

1. Brasil. Lei ${ }^{\circ} 9010$, de 29 de março de 1995. Dispõe sobre a terminologia oficial relativa à hanseníase e dá outras providências. Diário Oficial da União [Internet]. Brasília, p. 4509, 30 mar 1995 [acesso 23 mar 2021]. Seção 1. Disponível: https://bit.ly/3z1tiDA

2. Carvalho GB. Reis, papas e "leprosos". Belo Horizonte: Pelicano; 2004.

3. Browne SG. Lepra na Bíblia: estigma e preconceito. Viçosa: Ultimato; 2003.

4. Bíblia Sagrada. Versão de João Ferreira de Almeida. $5^{a}$ ed. Santo André: Casa Publicadora Paulista; 2005. p. 976.

5. Levantezi M, Shimizu HE, Garrafa V. Princípio da não discriminação e não estigmatização: reflexões sobre hanseníase. Rev. bioét. (Impr.) [Internet]. 2020 [acesso 23 mar 2021];28(1):17-23. DOI: 10.1590/ 1983-80422020281362

6. Claro LBL. Hanseníase: representações sobre a doença. Rio de Janeiro: Fiocruz; 1995.

7. Goffman E. Estigma: notas sobre a manipulação da identidade deteriorada. Rio de Janeiro: LCT; 1998.

8. Brasil. Lei $n^{\circ} 10.507$, de 10 julho de 2002. Cria a profissão de agente comunitário de saúde e dá outras providências. Diário Oficial da União [Internet]. Brasília, 11 jul 2002 [acesso 23 mar 2021]. Disponível: https://bit.ly/37WuRH4

9. Brasil. Lei $n^{\circ} 11.350$, de 5 de outubro de 2006. Regulamentação da profissão agente comunitário de saúde e de agentes de endemias. Diário Oficial da União [Internet]. Brasília, 6 out 2006 [acesso 23 mar 2021]. Disponível: https://bit.ly/3CXLel5

10. Silva JA, Dalmaso ASW. Agente comunitário de saúde: o ser, o saber, o fazer. Rio de Janeiro: Fiocruz; 2002.

11. Brasil. Ministério da Saúde. Política nacional de atenção básica. Secretaria de Atenção à Saúde [Internet]. Brasília: Ministério da Saúde; 2006 [acesso 23 mar 2021]. Disponível: https://bit.ly/3mdHS7v

12. Pinho LB, Kantorski L, Bañon-Hernández AM. Análise crítica do discurso: novas possibilidades para a investigação científica no campo da saúde mental. Rev Latinoam Enferm [Internet]. 2009 [acesso 23 mar 2021];17(1):126-32. DOI: 10.1590/S0104-11692009000100020

13. Fairclough N. Discurso e mudança social. Brasília: Editora UnB; 2001.

14. Resende VM. Análise de discurso crítica e realismo crítico: implicações interdisciplinares. Campinas: Pontes; 2009.

15. Arantes PCC, Deusdará B. Grupo focal e prática de pesquisa em análise do discurso: metodologia em perspectiva dialógica. Revista de Estudos da Linguagem [Internet]. 2017 [acesso 23 mar 2021];25(2):791-814. DOI: 10.17851/2237-2083.25.2.791-814

16. Kinalski DDF, Paula CC, Padoin SMM, Neves ET, Kleinubing RE, Cortes LF. Grupo focal na pesquisa qualitativa: relato de experiência. Rev Bras Enferm [Internet]. 2017 [acesso 23 mar 2021];70(2):443-8. DOI: 10.1590/0034-7167-2016-0091

17. Minayo MCS. O desafio do conhecimento: pesquisa qualitativa em saúde. 13ª ed. São Paulo: Hucitec; 2013.

18. Universidade Federal do Ceará. Padrões epidemiológicos, clínicos, psicossociais e operacionais da hanseníase nos estados do Maranhão, Pará, Tocantins e Piauí: uma abordagem integrada. Fortaleza: UFC; 2008. Relatório de pesquisa: Edital MCT/CNPQ/CT-Saude/MS/SCTI/Decit nº 034/2008.

19. Penna MLF. Tendência da taxa de detecção da hanseníase nas regiões brasileiras e unidades da federação: relatório técnico. Brasília: Ministério da Saúde; 2008.

20. Conselho Nacional de Saúde. Resolução $n^{\circ}$ 466, de 12 de dezembro de 2012. Aprova diretrizes e normas regulamentadoras de pesquisas envolvendo seres humanos [Internet]. Brasília: Conselho Nacional de Saúde; 2012 [acesso 23 mar 2021]. Disponível: https://bit.ly/3xYwpuS 
21. Helman CG. Cultura, saúde e doença. $5^{\text {a }}$ ed. Porto Alegre: Artmed; 2009. p. 367-73.

22. Foucault M. Vigiar e punir: nascimento da prisão. Petrópolis: Vozes; 1987.

23. Teixeira CSS, Medeiros DS, Alencar CH, Ramos AN Jr, Heukelbach J. Aspectos nutricionais de pessoas acometidas por hanseníase, entre 2001 e 2014, em municípios do semiárido brasileiro. Ciênc Saúde Colet [Internet]. 2019 [acesso 23 mar 2021];24(7):2431-41. DOI: 10.1590/1413-81232018247.19642017

24. Woortmann K. Quente, frio e reimoso: alimentos, corpo humano e pessoas. Cad Espaço Feminino [Internet]. 2008 [acesso 23 mar 2021];19(1):7-12. Disponível: https://bit.ly/3g9Cj6n

25. Silva AL. Comida de gente: preferências e tabus alimentares entre os ribeirinhos do Médio Rio Negro (Amazonas, Brasil). Rev Antropol [Internet]. 2007 [acesso 23 mar 2021];50(1):25-79. DOI: 10.1590/ S0034-77012007000100004

26. Cruz ES. O saber popular e o científico sobre as restrições alimentares no consumo de pescado, por pescadores do município de Maragogipe, Bahia [monografia] [Internet]. Cruz das Almas: Universidade Federal do Recôncavo da Bahia; 2018 [acesso 23 mar 2021]. Disponível: https://bit.ly/3yYTRt7

27. Lima MML, Silva TKR, Tsupal PA, Melhem ARF, Brecailo MK, Santos EF. A influência de crenças e tabus alimentares na amamentação. Mundo Saúde [Internet]. 2016 [acesso 23 mar 2021];40(2):221-9. DOI: 10.15343/0104-7809.20164002221229

28. Organização Pan-americana de Saúde. Álcool [Internet]. 2019 [acesso 23 mar 2021]. Disponível: https://www.paho.org/pt/node/4825

29. Garrido MCT, Pinho SR, Aguiar WA, Dunningham WA. Prevalência de alcoolismo e sintomas depressivos em pacientes da clínica geral na cidade de Salvador-BA. Rev Bras Neurol Psiquiatr [Internet]. 2016 [acesso 23 mar 2021];20(1):37-72. Disponível: https://bit.ly/3mbeRte

30. Filgueiras MIS. Percepção do profissional de enfermagem acerca da adesão ao tratamento da hanseníase [monografia] [Internet]. Cajazeiras: Universidade Federal de Campina Grande; 2019 [acesso 23 mar 2021]. Disponível: https://bit.ly/37UpJ6r

31. Ribeiro, MDA, Castillo IS, Silva JCA, Oliveira SB. A visão do profissional enfermeiro sobre o tratamento da hanseníase na atenção básica. Rev Bras Promoç Saúde (Impr.) [Internet]. 2017 [acesso 24 mar 2021];30(2):221-22. DOI: 10.5020/18061230.2017.p221

32. Silva DLG, Silva EG, Batista WA, Khouri AG, Oliveira RFS, Silveira AA et al. Novas perspectivas do diagnóstico e tratamento da hanseníase. RRS-FESGO [Internet]. 2019 [acesso 24 mar 2021];2(3):75-81. Disponível: https://bit.ly/3xYfPvb

33. Pekelman R. O agente comunitário de saúde se (trans)escreve. Saúde Redes [Internet]. 2016 [acesso 23 mar 2021];2(4):418-32. DOI: 10.18310/2446-4813.2016v2n4p418-432

34. Dantas DSG, Silva MRF, Torres RAM, Oliveira LC, Pinto FJM, Sampaio RMM. A formação dos agentes comunitários de saúde em educação popular: implicação na produção do cuidado na Estratégia Saúde da Família. Motricidade [Internet]. 2018 [acesso 23 mar 2021];14(1):157-63. Disponível: https://bit.ly/3ATVmtq

35. Pedraza DF, Rocha ACD, Sales MC. O trabalho educativo do agente comunitário de saúde nas visitas domiciliares em dois municípios do Brasil. Trab Educ Saúde [Internet]. 2016 [acesso 23 mar 2021];14(supl 1):105-17. DOI: 10.1590/1981-7746-sol00024

36. Cruz A. A inconformidade dos corpos e a doença no espaço público. Rev Electr Progr [Internet]. Cabo dos Trabalhos. 2007 [acesso 23 mar 2021];(2):1-31. Disponível: https://bit.ly/3D2K2Nw

37. Pereira JFG. A visita domiciliar do agente comunitário de saúde ao paciente com hanseníase [monografia] [Internet]. Sinop: Universidade Federal de Mato Grosso; 2019 [acesso 23 mar 2021]. p. 29. Disponível: http://bdm.ufmt.br/handle/1/1675

38. Oliveira CM, Linhares MSC, Ximenes Neto FRG, Mendes IMV, Kerr LRFS. Conhecimento e práticas dos Agentes Comunitários de Saúde sobre hanseníase em um município hiperendêmico. Saúde Rev [Internet]. 2018 [acesso 23 mar 2021];18(48):39-50. DOI: 10.15600/2238-1244/sr.v17n48p39-50

39. Simões MJS, Delello D. Estudo do comportamento social dos pacientes de hanseníase do município de São Carlos - SP. Rev Esp Saúde [Internet]. 2005 [acesso 23 mar 2021];7(1):10-5. Disponível: https://bit.ly/3zOY7bv

40. Cavaliere IAL, Grynszpan D. Fábrica de imaginário, usina de estigmas: conhecimentos e crenças de uma comunidade escolar sobre hanseníase. Cad Saúde coletiva [Internet]. 2008 [acesso 23 mar 2021];16(2):345-62. Disponível: https://bit.ly/37YOtKF 
Olga Maria de Alencar - Mestre - olgaalencar17@gmail.com

(D) 0000-0003-2477-7503

Thayza Miranda Pereira - Doutora - thayzinhamiranda@gmail.com

(D) 0000-0001-6979-947X

Jorg Heukelbach - Doutor - heukelbach@web.de

(D) 0000-0002-7845-5510

Jaqueline Caracas Barbosa - Doutora - jcaracas@ufc.br

(D) 0000-0001-6401-2244

Ana Suelen Pedroza Cavalcante - Mestre - anasuelen15@hotmail.com

(D) 0000-0002-2220-4333

Maria Rocineide Ferreira da Silva - Doutora - rocineideferreira@gmail.com

(D) 0000-0002-6086-6901

\section{Correspondência}

Ana Suelen Pedroza Cavalcante - Av. Dr. Silas Munguba, 1700, Itaperi CEP 60714-903. Fortaleza/CE, Brasil.

Participação dos autores

Olga Maria de Alencar participou de todas as etapas do estudo, concebendo-o com Thayza Miranda Pereira, Jorg Heukelbach e Jaqueline Caracas Barbosa. Ana Suelen Pedroza Cavalcante e Maria Rocineide Ferreira da Silva contribuíram com a discussão e análise crítica do texto. Todos os autores revisaram a versão final do manuscrito.

Recebido: 13.4 .2020

Revisado: $\quad 5.8 .2021$

Aprovado: 9.8 .2021 